\title{
Scaffolding students' preparation for a pharmacology practical improves their self-efficacy and learning
}

Johanne Juel Callesen, Department of Molecular Medicine, University of Southern Denmark Karin Hjernø, Department of Biochemistry and Molecular Biology, University of Southern Denmark Lotte O'Neill, SDU Centre for Teaching and Learning, University of Southern Denmark Stine Sonne Carstensen, Department of Molecular Medicine, University of Southern Denmark Maria Bloksgaard', Department of Molecular Medicine, University of Southern Denmark

\begin{abstract}
Laboratory practicals are important learning elements in science teaching. We used principles of active learning to develop interactive online teaching materials to scaffold students' preparation for a simulated pharmacology practical. We aimed at increasing students' self-efficacy and evaluated the effect of the intervention qualitatively and quantitatively. The online material contained elements of formative assessment for the students to follow their learning progress. Students' readiness for the practical was assessed through a mandatory multiple-choice test. Students $(73 \%)$ agree or strongly agree that the course of the practical increased their competences in pharmacology. We infer from the evaluations that the interactive material increased students' self-efficacy, informed refinement of the conceptual understanding of pharmacology and increased their ability to apply content knowledge to solve the inquiries for the practical. The pedagogical principles, e-learning tools and learning elements demonstrated in this development project can be used in many other educational contexts and disciplines.
\end{abstract}

\section{Introduction}

The laboratory as a learning tool

Laboratory practicals are cornerstones in science teaching. When designed carefully, practicals contribute to an effective learning environment, teaching students the processes of science; developing a hypothesis, designing experiments with proper controls, and often, the practicals also provide students' hands-on laboratory experience with the theoretical parts of a science topic. Recently, with the development of more sophisticated educational IT resources, the replacement of wet laboratory practicals with computer simulation exercises has shown to be particularly useful to support students' learning of difficult concepts and scientific inquiry selfefficacy (Goudsouzian et al., 2018; Husnaini \& Chen, 2019; Reece \& Butler, 2017). Replacing a wet laboratory

\footnotetext{
1 Contact: mbloksgaard@health.sdu.dk
} 
with a virtual laboratory will, following an argument of authenticity, still provides learning from the laboratory, but there will of course be some loss of reality from the wet lab (Dahl et al., 2013). However, the advantage of the virtual laboratory is that students can focus on learning the essential parts of theory, rather than focusing on how to use the hardware (Kolil et al., 2020; Rutten et al., 2012). Additionally, time, resources and, in some cases, live animals, are saved, and students are provided the opportunity to design their own experiments as well as to repeat failed experiments. This is not possible when using live tissues in classical wet pharmacology practicals.

Pharmacology A is a 5 ECTS mandatory course for 3rd year biomedical students at the University of Southern Denmark. Two of the intended learning objectives of the course are: 'explain the mechanisms of action of common drugs acting on smooth muscle cells in e.g. the vascular system' and 'design relatively simple laboratory experiments to evaluate the effect of drugs, hereunder also the effect of agonists in the presence and absence of antagonists'. In the course, both lectures and small classroom/problem-solving teaching cover these learning objectives. These are followed by a computer simulation exercise simulating real-life experiments on a rat aorta, a classical preparation used for studying receptor pharmacology. The practical is implemented as a learning activity in the pedagogical strategy to promote the students' acquisition of highest order thinking skills in pharmacology cf. Blooms taxonomy (Anderson \& Krathwohl, 2001; Churches, 2008), i.e. critical thinking, planning and execution of experiments to test hypotheses, presenting and interpreting results, discussing, communicating and concluding on experiments.

\section{The pedagogical challenges}

The computer simulation exercise is conducted using Virtual Physiology's SimVessel@ software module (Philipps University of Marburg, Engineering Office of Biomedicine and Technology, Marburg, Germany) running on the students' individual computers via an institution license. 84 students used this software for the first time at the University of Southern Denmark in the spring of 2019. The scaffolding of the students' learning around the practical followed tradition; the students were handed out the lab manual and attended a mandatory two-hour introductory lecture, after which they were allowed access to the practical. During the practical and in the course evaluation at the end of the semester, it was clear that the students did not perceive the practical as an element contributing to their learning in pharmacology. 53 students participated in the course evaluation; $80 \%$ hereof indicated that they disagreed (24\%) or strongly disagreed (56\%) that they knew what was expected of them in the practical. Only $34 \%$ agreed that the practical had an added value relative to lectures and small classroom teaching, and only $16 \%$ agreed or strongly agreed $(2 \%)$ that the practical was of added value for their learning of pharmacology (Figure 4). Several frustrated free text statements supported the quantitative evaluation.

(I) 'We did not really learn anything from the practical, because the program itself [SimVesse/ $O$, author] was difficult to use and this took up all our time.' (Student $A$, June 2019)

(II) 'A computer simulation exercise would be a good supplement to the course if we had more time, e.g. a preparatory class, in which we were taught how to calculate and how to do the experiments.' (Student B, June 2019) 
(III) 'We used way too much time to figure out how to do our calculations before starting the experiments. Generally, we were confused about what to do and how to prepare.'(Student $C$, June 2019)

The instructors in the classroom where the students met for group work during the computer simulation exercise, confirm the observations in the course evaluation. The students were clearly frustrated that they were not able to conduct the experiments, and the number and characteristics of the questions asked made it clear that the students had limited ideas of what was expected of them, and what they were supposed to do. Several students had not installed the software required for performing the exercise before showing up, although they were instructed to do so during the introductory lecture.

This led to discussions on possibilities and pedagogical strategies to better scaffold the students' preparation for the lab practical, i.e. provide them with temporary assistance to complete a task or develop new understandings, so that they would later be able to complete similar tasks alone (cf. (Hammond \& Gibbons, 2005), p. 9). To approach this challenge, we i) invited students from Pharmacology $A$ in the spring semester of 2019 to contribute to the discussion and design of the material and ii) decided that the practical had to undergo significant changes, including commissioning effective pedagogical and didactic tools. Here, we describe the intervention (the preparatory scaffolding of the lab exercise), the students' experience with this and their experience and perceived learning outcomes of the subsequent lab exercise. One student from Pharmacology A in the spring semester of 2019 volunteered to contribute to and prepare the material.

\section{Pedagogical and didactic considerations}

Educational IT has at several instances been reported to support students learning of scientific concepts (Costabile, 2020) and to support the preparation for laboratory practicals (Blackburn et al., 2019; Dyrberg et al., 2017; Kolil et al., 2020; Makransky et al., 2016; Thisgaard \& Makransky, 2017). With the practical already being a computer simulation exercise, it was natural to consider online materials to support the students' learning process. The impact of virtual environments on students' self-efficacy has been highlighted on several earlier occasions (Husnaini \& Chen, 2019; Kolil et al., 2020; Weaver et al., 2016; Wilde \& Hsu, 2019). Students with a higher self-efficacy have greater confidence that they can complete a given task successfully, and this confidence is associated with increased motivation and persistence during difficult tasks, a higher level of well-being and increased performance (Bandura, 1997). The most effective way of inducing self-efficacy in students is to scaffold their enactive attainment: experiencing their own success increases self-efficacy, whereas experiencing failure has the opposite effect. To see peers succeed ('vicarious experience') or to be encouraged by peers ('social persuasion') can also induce a feeling of self-efficacy, but both are less effective compared to a concrete mastery experience (Klassen \& Klassen, 2018). To allow students to monitor their learning progress, they need feedback. Feedback is one of the cornerstones of active learning (Medina, 2017), the other three being: i) activation of prior acquired knowledge, ii) involvement of most/all students and iii) promoting students' metacognition and reflection. Thus, to scaffold the students' preparation for the practical and to make sure all students had a certain level of prerequisite knowledge required to complete the tasks in the practical, we decided to develop interactive teaching material with successive, formative self-assessments (small quizzes) allowing continuous feedback on the students' learning progress. To formally assess the students' preparedness for the practical, their learning was assessed by a mandatory electronic multiple-choice test. The effect of the strategy was evaluated during the course evaluation in the spring of 2020 (in comparison with that of the spring of 2019) and through specific 
questions included in the template of the reports handed in by the students for summative assessment following completion of the experiments in the computer simulation exercise.

\section{Method}

\section{Pedagogical and didactic approach}

The computer simulation exercise is divided into 2 parts, separated in time. During the first part, the students perform introductory exercises to prepare the experimental protocol, i.e. they write the laboratory protocol for the second part of the exercise. This protocol is approved by the instructors, and the planned experiments are conducted during the second part of the exercise. The results from the conducted experiments are submitted as a laboratory report for final summative assessment by the course leader (pass/fail grading). The students are allowed and encouraged to work in teams of 3-4 to ensure collaborative learning through peer feedback.

Traditionally, the contents of the practical, the theoretical frame and required pharmacological background knowledge are introduced during a classical two-hour lecture and in the laboratory manual. Students' knowledge prior to the exercise is not evaluated; however, their understanding of the whole exercise including background knowledge is evaluated through the laboratory reports. In the spring of 2020, we replaced the introducing lecture and large parts of the manual with interactive learning materials made in Articulate Rise 360 (Articulate Global, 2020) to introduce and scaffold the practical. The students' understanding of the theory behind the practical, their use of the simulation software and the other contents in the Rise 360 material were tested using a formal, summative multiple-choice test with a requirement of $80 \%$ correct answers to pass before proceeding to the experiments in the practical. All remaining parts of the practical were unchanged.

\section{Design of the interactive teaching material}

The interactive teaching material was prepared using Articulate Rise 360 (Articulate Global, 2020). Rise 360 provides the user with the possibility to make creative lessons with different contents. Lessons are divided into sections, and in each section, the teacher can place several elements, like text, pictures, videos or activities where the student must click for more information, match or pair elements or answer small science quizzes. The software is browser-based and runs under an institution license. The student involved in the preparative discussions enrolled in a 15 ECTS individual study activity to develop the interactive teaching material. She was granted access to the course at a similar level as the laboratory instructors and followed the students' reactions to using the software throughout the course of the practical. To make the material personal, there is a short virtual greeting from her along with a short introductory text about the team responsible for the software. Additionally, the contents of each lesson are presented using a pedagogical assistant, an on-screen character who helps guide the learning process during instructional episodes; in this case a technician named Isabel (Figure 2). This personalisation of the software, together with the virtual greeting from the student who made the material, was chosen to support the embodiment principle that students learn better from online assistants that use human-like gestures and movements (Clark \& Mayer, 2011). Following the initial introduction of the interactive material, users can move to the next section using a navigation pane always visible at the left side of

\footnotetext{
${ }^{2}$ Link to the interactive teaching material (in Danish): https://rise.articulate.com/share/MjuR6Wob3RzBXTIIIof7ifNBp dqNafe
} 
the screen or via a 'continue' button at the bottom of the page. Videos for the material were recorded using the inbuilt screen recorder on Apple iPad or QuickTime Player (7.6.5 for Mac, Apple Inc).

\section{Contents of the interactive teaching material}

At first, when students open the link to the Rise 360 material, they meet the introductory text that explains how the material is organised and how to use it. Included here is the virtual greeting from the student that made the material (Johanne, 1st author of the paper), in which she explains why she got involved in the project and introduces the team behind. The contents of this video are not part of the syllabus but serve as personalisation of the material. Next, the four main lessons are shown, including several sections, divided by topic, to make navigation easier (Figure 1). The four lessons are presented by the pedagogical assistant, Isabel.

The first lesson 'Aim and understanding of the practical' contains four sections. Following the initial introduction in section one, the lesson continues with section two, explaining the theory about the rat aortic ring preparation. Here, pictures are used, each accompanied by a short, explanatory text. The section is rounded off with an interactive element in which the student actively categorises words according to his/her understanding of the introduced theory (match the correct). When the quiz has been submitted, the student is immediately informed about the result and can repeat the test and check the theoretical part again, if needed.

The third section in lesson one links to a video from the Journal of Visualized Experimentation, which shows how a wet laboratory experiment with a rat aorta ring preparation is performed (Jespersen et al., 2015). This element is included to visualise for the students that the computer simulation exercise simulates a real-life experiment but without the need to sacrifice an animal. To further introduce the students to the experimental setup, a cartoon of the experimental setup is provided with clickable numbers (Figure 3a). This activity contains a forced activation element: The students are not able to complete the lesson unless all elements have been reviewed since understanding the experiment simulated by the software is an essential part of the practical. Finally, the lesson is completed with a few quizzes, which provide the students with formative feedback on their immediate learning.

The remaining three lessons are constructed similarly, with sections containing activating elements (click and learn, forced activation elements), small videos and quizzes. As an example, an instructional video explaining the use of the SimVessel ${ }^{\circ}$ software is included in which Johanne ( $1^{\text {st }}$ author of the paper) explains an example of an experiment. The templates to be used for calculations are also explained using short videos, which show the actual use of the worksheet and how to make a graphical representation of the raw data. 


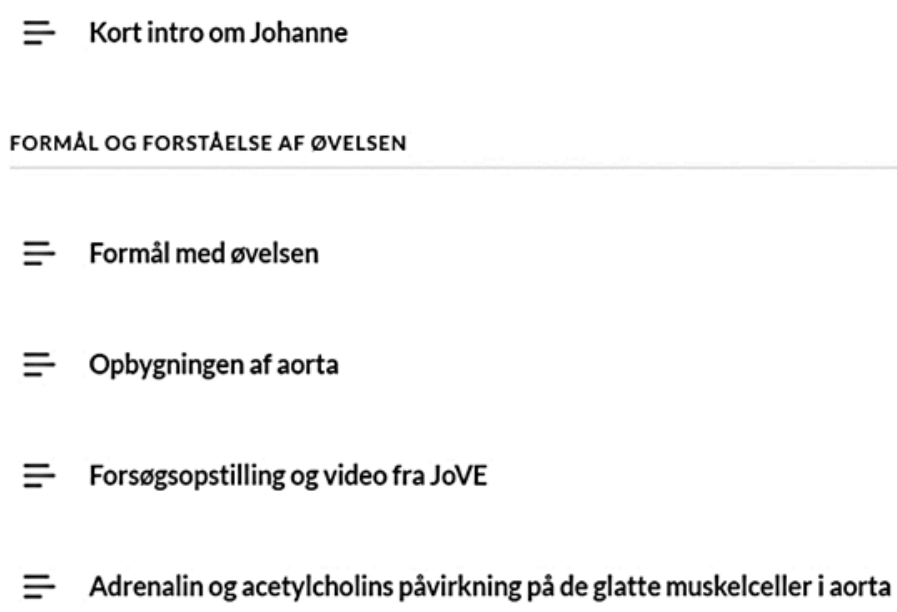

Figure 1: Overview of lessons and sections in the interactive teaching material made using Rise360. When the student has completed a lesson, it is highlighted by a tick in the circle next to that particular lesson and section title. The four main lessons are 'Aim and understanding of the practical' ('Formål og forståelse af øvelsen'), 'Pharmacodynamics' (Farmakodynamik), 'SimVessel' (How to use the simulation software) and 'Excel Template' ('Skabelon i Excel', a template required for the data calculations). 
Figure 2: Presentation of Isabel, the pedagogical assistant guiding the students' learning process in the Rise360 software. Isabel is a technician and will show up frequently to guide the students' journey through the interactive material. She welcomes the students ' $\mathrm{Hi}$, my name is Isabel. I will help you get started on the computer simulation exercise in Pharmacology A. In this first lesson, I will explain the aim of the practical'.

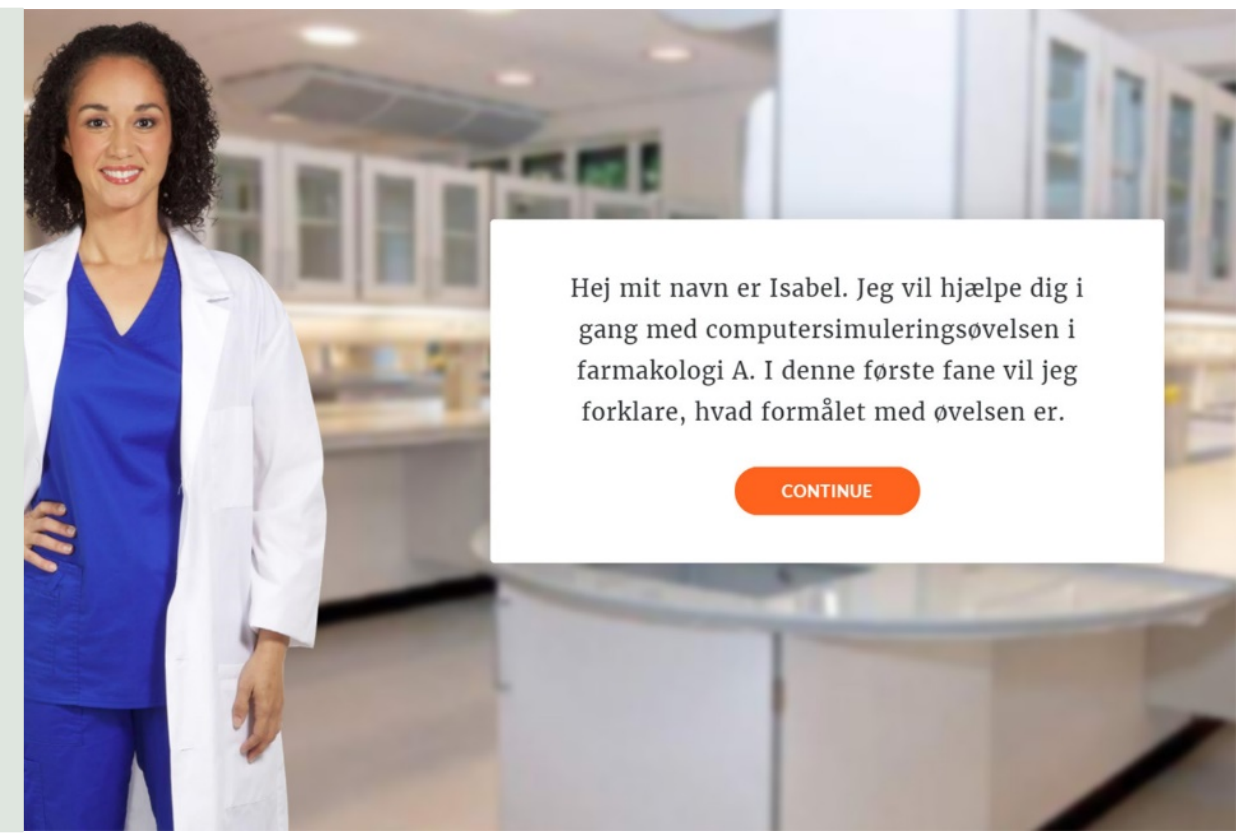

A

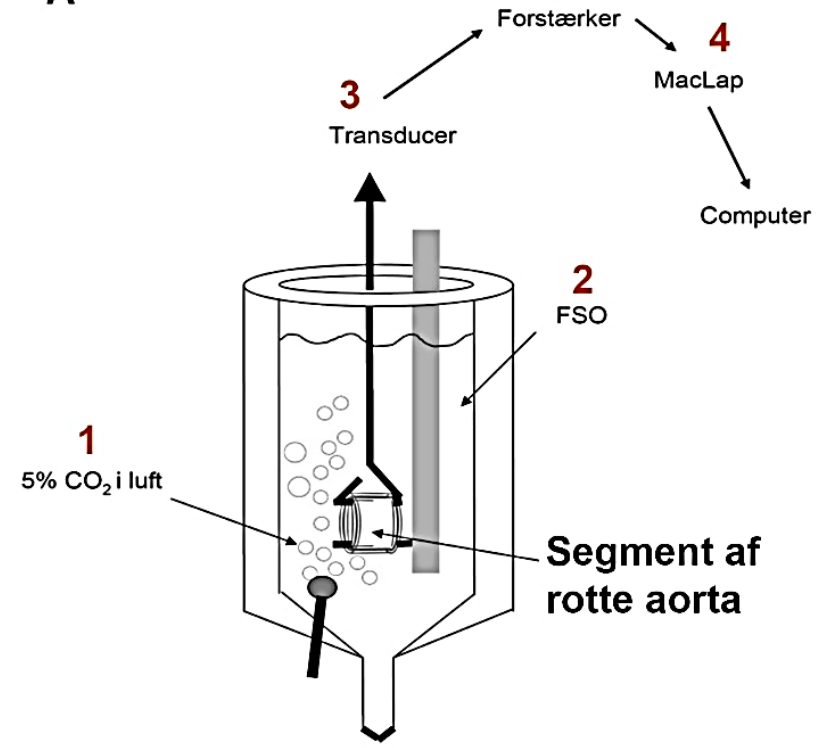

B

Hvad måler den isometriske krafttransducer?

Tension

Forskel i længden af aorta

Stræk

Figure 3: Example from the interactive software showing a forced activation activity. A) the experimental setup (segment of rat aorta) simulated in SimVesse ${ }^{\mathbb{O}}$ with clickable numbers, each showing a short explanatory text about the specific component in the setup (1.5\% $\mathrm{CO}_{2}$ in air, 2. Buffer, 3. Transducer, 4. MacLap). B) example of a question used for a formative assessment of the students' understanding of the experimental setup in A ('What is the output of the isometric force transducer?' $\cdot$ Tension, $\bullet$ Difference in length of aorta, $\bullet$ Stretch). 


\section{Summative assessment of the students' readiness to learn before the practical}

Before the students are allowed access to the practical, they must pass an MCQ test by answering at least $80 \%$ of the 25 questions correct. Around half of the questions focus on essential parts of the theoretical background of the practical, while the remaining questions partly focus on the practical use of the simulation software and partly on the calculations required for the data analyses. The test is open for 2 hours, and all aids are allowed, except working in teams, to answer the questions. In the event of a failed test, the student is offered 2 consecutive chances to pass.

\section{Students' evaluation of the interactive teaching material}

To evaluate the Rise 360 material and the effect of it on the students' perceived learning, we incorporated the 5 questions below in the report template. Students were informed that answering the questions did not influence their grades. The students were asked:

i) how many times they went through the interactive material (full or parts of)

ii) when they used the material (before, during and after the experiments)

iii) what was particularly helpful

iv) what impact the software had on their learning

v) to provide suggestions for improvements of the interactive material before using it another time.

In addition, we used the course evaluation, which contained 4 questions regarding the SimVesse ${ }^{\circ}$ practical in both 2019 and 2020. Students were asked to provide a score on a Likert scale (Likert, 1932) between 1 (strongly disagree) and 5 (strongly agree) on the following statements:

i) I knew what was expected from me

ii) the practical provided me another way of learning pharmacology

iii) group work worked out efficiently

iv) the practical improved my competencies/my learning in pharmacology.

Students could write comments on open-ended questions as well to substantiate their quantitative evaluations.

Instructors' evaluation of the effect of the Rise 360 material and summative assessment of the students' learning outcome.

Instructor 1 was involved as instructor in both 2019 and 2020 and provided upon request a subjective description of his experiences during both practicals. Instructor 2 was a new assistant on the lab practical 2020 and used the interactive learning material to prepare for the practical. She provided an additional review of the interactive material. Both instructors provided an overview of the number of reports handed in and the number of reassessments of the reports required for the students to pass the practical; Instructor 1 provided overviews for both 2019 and 2020. 


\section{Planned observations during the lab practical}

Originally, we planned to conduct the computer simulation exercise in the spring of 2020 in the same way as we did in the spring of 2019, i.e. meeting physically with the students. However, due to the COVID-19 lockdown in the spring of 2020 , we were forced to conduct the activity as a $100 \%$ online event. The physical interaction with the instructors was replaced by an online discussion board, where students could ask questions regarding any contents of the practical.

\section{Ethical considerations and approval}

The Data Protection Officer and a lawyer from the University of Southern Denmark Research and Innovation Organisation (RIO) approved the implementation of the project along with a collection of the students evaluations without the students' written consent. The reasoning behind this approval was that i) all involved parties were informed about the current GDPR regulations and agreed to follow these, ii) from i), it followed that in order to maintain complete anonymity of students, all relevant information from the course evaluation and laboratory reports was extracted (copied) to a new document where all comments were anonymised and placed in random order and iii) all data, -although not possible to attribute to an individual student - were treated as if they were personal data, i.e. stored on safe data servers with logging. Both instructors provided their written consent to confirm the use of their statements and opinions in the project and this paper.

\section{Results}

Formal summative test of the students' learning before the practical (preparation phase)

In the spring of 2020, 41 students participated in the SimVessel practical. All students passed the MCQ test using only one attempt. For 13 of the 25 MCQs, more than $95 \%$ of the students answered correct. For 8 questions, 85$95 \%$ of the students answered correct, for 3 questions $75-85 \%$ answered correct, and in one question, less than $25 \%$ answered correct.

\section{Students' qualitative evaluation of the interactive learning material}

From the students' comments in the laboratory reports, it is clear that using the material was a great help both for the students' preparation and for the execution of the experiments in the practical. Of the 14 groups handing in their reports for the final assessment (41 students), 2 groups indicated that they used the interactive material once or twice, 5 groups that they used it 3-4 times and 7 groups that they used the material more than 5 times. All groups completed all 4 lessons in the interactive material before the MCQ test, and all used selected sections during and after the experiments. Ten of the 14 groups highlighted that the videos explaining the practical use of the SimVessel software and the calculation templates made the greatest difference. The representative examples of comments from the students' reports below illustrate this.

IV) 'The interactive material was used several times during the weeks of the practical; the first time was before the mandatory MCQ test when the whole material was studied. Subsequently, the material was used continuously; for example, before starting the experiments in SimVessel, the video with the example from SimVessel was reviewed. The theory about the structure of aorta and the effect of adrenaline and acetylcholine on the smooth muscle cells in aorta was used for theory. The lesson 
about how to use the calculation templates in Excel was used several times during data calculations. Generally, it was really nice that the interactive material was organised in lessons and sections since we could then use it as reference work.' (Group X, April 2020)

V) 'Before we started the experiments, the interactive material provided us with a good overview and a really solid understanding of how to perform the experiments. It also worked well that theory was explained first, followed by a small exercise. This gives a better understanding of the contents. We think it all worked out well. The format made it more interesting. The quality was good, it was easy to get an overview since no excess information was included. Explanations of figures and signalling pathways were detailed and increased our understanding of the theory. We actually believe that we have learned more from this than from a normal lecture. Here, you can learn at your own pace, and you can go back and go through parts you are in doubt about or did not understand at the first time. Johanne is to be commended for the interactive teaching. The videos about how to make CCRCs and Schild Plots were really great. It was easy to understand. It is the first time we are so positively surprised about teaching!'(Group Y, April 2020)

Six groups highlight the quizzes as having a positive effect on their learning, and 4 groups that the sections with theory about the physiology and pharmacology of the rat aorta worked best for their learning. This is illustrated by the following quote:

VI) It was really great having questions after a small theoretical section. In this way, we received an impression of whether we understood the theory. It is nice having both videos and text, the mix caught your attention in a new way and you had the topic explained differently'. (Group Z, April 2020)

When asked how the material supported the understanding and completion of the exercises, 10 of 14 groups highlighted that the interactive material provided the necessary overview, while 4 groups highlighted that they saved precious time. 3 groups stated that the interactive material was effective in connecting theory and practice. The students were good at providing constructive feedback with respect to which parts of the material that should be improved before using it another time. For example, some groups mentioned that there were a few confusing discrepancies between the written instruction manual and the interactive material, and a few instances where functions in the simulation software were not described. The following quotes are examples of constructive feedback from the students.

VII) It would have been great if you had mentioned that you could change baseline in the software and that you should not re-zero following administration of antagonist.' (Group P, April 2020)

VIII) We had problems figuring out how to add antagonist. It was easy to follow the explanation on how to add agonist, but we missed the one for antagonist.'(Group Q, April 2020) 
IX) It was a nice video about the Schild Method, but we missed some interaction. It would have been nice if the video had been followed up with questions, so that we could test our understanding.' (Group R, April 2020)

\section{Scaffolding students' preparation for the lab practical increased their perceived success}

The lab practical was evaluated in the course evaluation in the spring of 2019 and 2020. In the spring of 2020, 30 of 40 students completed the course evaluation. The Likert scores for the four statements are summarised in Figure 4. It is seen that for all four statements, the percentage of students agreeing with the statements, i.e. positiveness towards the SimVessel ${ }^{\circ}$ exercise, increased in 2020 compared to in 2019.

A

I knew what was expected from me for the lab practical

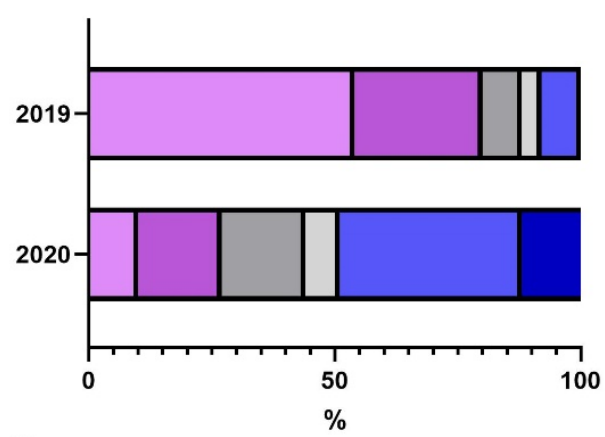

C

The group work worked out well

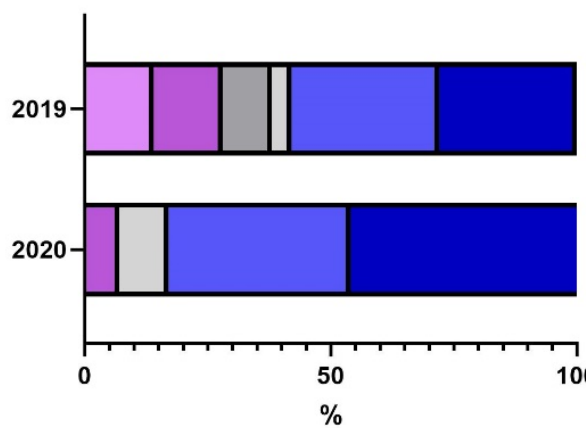

strongly disagree
B Working with the lab practical made me able to acquire the knowledge in a different way

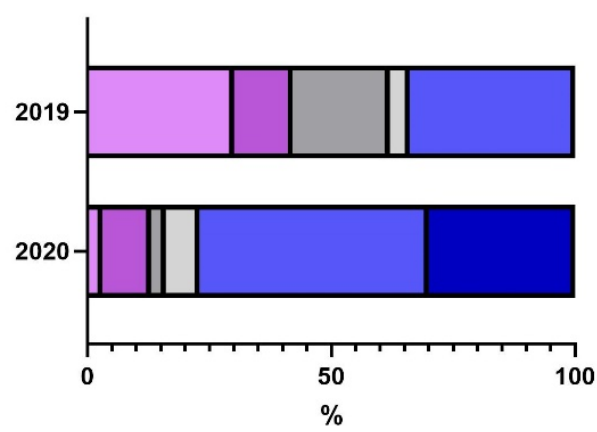

D

The lab practical improved my competencies / my learning in pharmacology

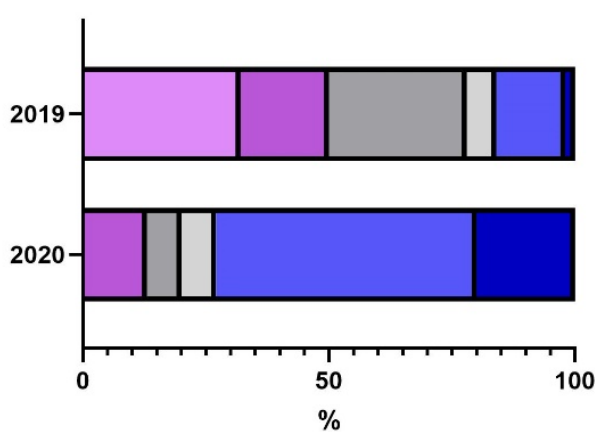

neither/nor

Figure 4. Students' quantitative evaluation of the computer simulation exercise. Students provided a score between 1 (strongly disagree) and 5 (strongly agree) on the indicated statements (A-D). The answers are based on 53/84 (63\% of total enrolled students) and 30/41 (75\% of total enrolled students) students' evaluation of the course. The results are presented as \% of answers.

Overall, the Likert scores support the impression from the students' feedback in the laboratory reports that the interactive material made a positive difference for the students' preparedness for the practical (Figure 4A), their learning of pharmacology (Figure 4B) and their competencies in pharmacology (Figure 4D). Although Figure 4C 
indicates that the group work worked out well, and even better in 2020 compared to 2019, it is also clear from the free text comments that despite the positive impact of the interactive material, the students needed additional feedback. Specifically, the students highlight that it was difficult to get immediate feedback from the instructors and that meeting online was a challenge. These challenges have been exceptional in 2020 due to the COVID-19 lockdown. This is illustrated by the quotes below.

X) 'The interactive material was essential for understanding the practical, the theory behind and how to perform the experiments, especially since it was impossible to show up physically at the university to get help from an instructor.' (Student A, June 2020)

XI) It worked really well with the interactive material, but information clarifying how much we should include and to which detail was missing.' (Student B, June 2020)

XII) 'Due to Covid-19, it was not possible physically to get help for the practical, and sometimes the response time on Discussion Board was long. It would have been an advantage if the teachers had provided some dates and timeslots with Zoom meetings since it is often easier to understand what is meant by a question and with an answer when sitting face to face.'(Student C, June 2020)

\section{Effect on the instructors' workload and instructors' qualitative evaluation of the students' preparedness}

The two instructors in the practical both provided a short, written statement on their experiences during this year's practical. Instructor 1 furthermore provided a comparison between events in 2020 and 2019. In general, instructor 1 described that despite the COVID-19 lockdown, the 2020 students were better prepared and performed better, compared to the 2019 cohort. Instructor 1 highlighted that students were more confused about the use of SimVessel in 2019, whereas his impression in 2020 was that the students had a better understanding of how to use the simulation software. Instructor 1 also provided numbers showing that while $63 \%$ of the students used only one attempt to have their written report approved in 2020, this was only the case for $33 \%$ of the students in the spring of 2019 . Likewise, $38 \%$ had their laboratory protocol approved at the first attempt in the spring of 2020, while this was only the case for $11 \%$ in the spring of 2019. Instructor 2 was a new instructor in the lab practical in 2020 and indicated that only 3 of 8 teams had to revise their report before approval, supporting the success rate described by instructor 1 . Thus, the instructors' workload decreased due to the increased preparedness of the students. Instructor 2 used the interactive material for preparation similarly to the students and indicated that at first hand, it was difficult to get an overview of all the material available. She suggested using a short introductory video to explain how everything is organised (instruction manual, interactive material, templates) for the next time along with a detailed overview of deadlines and requirements.

\section{Discussion}

We implemented interactive learning material to scaffold students' preparation for a laboratory practical in pharmacology. The material was developed following the principles of active learning and made use of a pedagogical assistant to increase learning. We actively used formative tests to enhance students' self-efficacy. From the evaluation of the intervention, it is clear that the interactive material to a much better extent scaffolded students' preparation for the practical, compared to classical lecturing. Students give the impression that they learn better using the interactive software, especially through the quizzes providing instant feedback of the 
individual students' learning progress. The formal, summative assessments of the students' preparedness (the MCQ) and the laboratory reports support this.

\section{Active e-learning and assessment for learning as tools to increase self-efficacy}

The online, interactive teaching material provides the students with the possibility to actively prepare for the computer simulation exercise, while providing them feedback on their learning through the interactive elements. The quizzes force the students to reflect on the scientific content and they may review each topic several times if needed for answering correct. This is most likely to activate knowledge (schema activation) and bridge earlier knowledge with new knowledge through an active process (Ausubel, 1967). Being able to go through the material several times is an advantage compared to the classical introductory lecture, held once and offline. Scaffolding the students' preparation for the practical through interactivity resulted in the students achieving a better content knowledge and - through the repeatedly prompted reflections on their learning - a better conceptual understanding of pharmacology. This allowed them to think critically in their planning and execution of experiments and resulted in less questions for the instructors. Finally, fewer groups needed to hand in reports several times, i.e. the students' abilities to discuss, communicate and conclude on experiments improved.

We actively used assessment for learning (Hattie, 2009) as an important tool to increase students' self-efficacy, i.e. their confidence in their ability to reach targets through hard work and determination, which contributed to the success of the learning intervention. Assessment for learning is an approach to teaching and learning which uses feedback to improve students' performance (Williams, 2011). Generally, assessment serves three main functions: i) judging the quality of learning achieved by the students, ii) certification of achievements (e.g. grade reports or diploma) and iii) supporting the learning of the students (Bjælde et al., 2017). Here we used different levels of assessment. First, during the students' preparative phase, inbuilt in the Rise 360 material, a formative assessment in the format of small quizzes was used as a feedback/feedforward tool supporting students' learning through the provision of immediate feedback on their level of competencies, revealed by the quiz responses. Second, summative assessment was used to judge students' learning by MCQs. This test was graded (pass/no-pass), and $80 \%$ correct answers were required to pass and proceed with the laboratory practical.

Through the continuous feedback, students become more involved in the learning process and from this gain confidence in what they are expected to learn and to what standard. According to the self-efficacy theory, expectation-performance differences increase if obstacles occur (Bandura et al., 1996; Weinberg et al., 1979). Thus, if students expect the laboratory practical to be very difficult, due to a lack of overview and confusion about what is expected, then the students' performance decrease due to negative expectations about their abilities and the accompanying frustrations. In contrast, finishing the preparations for the practical with a good summative assessment is likely to increase students' belief in their own abilities and their self-efficacy in connection with the work to be performed during the period of the practical. In connection with the small formative quizzes in the interactive material, we used a mandatory MCQ test. As summarised above, all students passed the test at their first attempt, for most students with almost no wrong answers. In a formal exam, where the results (grade) of the assessment would be used to certify students' achieved learning, the test would not have been useful, as the questions were too easy to answer (Tobin, 2020). However, here, the use of an obligatory test element adds to an increased student self-efficacy since the feedback (a good test-score) constitutes a selfexperienced mastery experience (Bandura, 1997). Using the interactive online material, students are more involved in the learning process, and through this, they gain increased insight and understanding with respect 
to what is expected from them and at which level. Although we did not assess directly whether students' selfefficacy increased, our results are in line with several earlier studies showing that virtual environments increase students' self-efficacy (Dyrberg et al., 2017; Husnaini \& Chen, 2019; Kolil et al., 2020; Makransky et al., 2016; Thisgaard \& Makransky, 2017; Weaver et al., 2016; Wilde \& Hsu, 2019). The positive effect on students' learning is reflected in the feedback provided by the instructor assisting with the practical in both 2019 and 2020, reporting that the students in the spring of 2020 seemed to better understand the theory as well as contents of the computer simulation exercise and worked more independently. Importantly, this resulted in fewer reassessments of the students' laboratory protocols and reports in the spring of 2020.

\section{Peer and teacher feedback is important for learning}

When we planned to use the interactive teaching material, we did not know about the major lockdown to come due to COVID-19. Having the online, interactive material available turned out to be essential for the completion of the practical as a learning experience. It should, however, not be neglected that the students, despite experiencing a good effect of standardised, automatised formative assessments, need the possibility of individualised and differentiated feedback to have a good $360^{\circ}$ experience of the laboratory practical (Harden $\&$ Laidlaw, 2013). Providing the students with the possibility to receive online, real-time feedback could likely have saved the last few frustrations and could have provided the possibility to ask for further explanations in cases where the written answer to questions did not provide all the necessary information for the student to fully understand the problem explained. (Furberg, 2016) has shown that interaction between the students and the teacher is important for computer-based collaborative learning. The interaction between the students and their science teacher is an important resource that cannot be replaced $100 \%$ by online, interactive learning materials. Individualised feedback is important since students learn differently, and these differences cannot always be met by standardised formative feedback. This is supported by both the students' and instructors' statements that online meetings, or even physical presence at the university, could have saved many mails back and forth. In addition, the possibility for the students to be in a room with instructors available while performing the experiments could have met quite a few of the challenges on the fly.

\section{Cost-benefit analysis and study limitations}

We used Articulate's Rise 360 software to develop the interactive teaching materials. The software is easy to use, the design process is intuitive, and publishing is easy. It took around 3 weeks to make the whole learning module

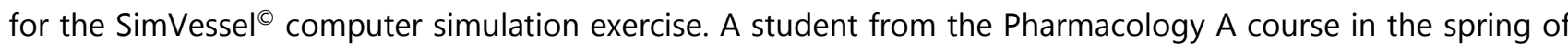
2019 made the software in collaboration with the responsible teacher (content and pedagogical principles), an e-learning consultant (how to use the software), a pedagogical consultant (pedagogical principles) and the course's teaching secretary. The team used approximately 3 hours to coordinate efforts. In addition to this comes the time used to make videos, figures, quizzes, etc. These investments are one-time investments. The interactive material can now be refined in line with the students' constructive feedback and can be amended for use in other courses, e.g. for pharmacy students. A license for Rise 360 costs around DKK 5,000 (USD 780 or EUR 670) and can in parallel be used for the construction of interactive learning elements in different courses. In our opinion, the benefits for the students, the instructors' and teacher's lower number of working hours used for the re-assessment of laboratory protocols and reports balance out the investments. It is our clear impression, qualitatively as well as quantitatively, that the students gained more from the computer simulation exercise after using the interactive material. We infer from the evaluation that scaffolding the students' preparation for the lab 
practical increased their self-efficacy, and consequently, also their learning outcome. Our study is limited in the sense that we primarily report on qualitative findings; we have not performed systematic measurements of the students' self-efficacy, and our study group is rather small.

\section{Transferring what we learned to other disciplines}

We believe the principles we used can be generalised and applied in many more educational situations and disciplines. The success is founded on the following three generic pillars:

i) Scaffolding. We provided the students with temporary assistance to complete a task and develop new understandings. In the interactive material, we set the stage for learning step-by-step and provided continuous feedback (cf. above). This ensured preparedness (in our case for the practical) and readiness to build on prior knowledge.

ii) Active learning. Using the interactive software, the students apply their former learning from lectures and small classroom teaching. All students can participate, and they do this at their own pace. They activate their knowledge and test their understanding through quizzes and other interactive elements.

iii) Feedback-feedforward. The use of quizzes in the software provides instant feedback on the learning process for each student. The obligatory MCQ test - a summative test from the students' point of view, but pedagogically, the test is used formatively - provides students with a self-experienced success and thereby help them move forward, enhancing students' self-efficacy. Additionally, the group work promotes collaborative learning through peer feedback. It should not be neglected that students also need personal, real-life feedback from the teacher.

\section{Conclusion}

Using educational IT, we scaffolded students' preparation for a laboratory practical in pharmacology. Scaffolding the students' preparation for the practical enhanced learning and better conceptual understanding of pharmacology: The students' abilities to plan, discuss, communicate and conclude on experiments improved, and thus, fewer groups needed to hand in reports for reassessment. In the evaluation, students emphasise an appreciation of being able to work at their own pace, receiving feedback/feedforward from the interactive elements, and their expressions indicate perception of an increased learning outcome using the material. Although not evaluated through objective measures of attainment, we infer from these findings that scaffolding students' preparation for the pharmacology practical increased their scientific content self-efficacy and experienced learning outcome.

Our study is limited by our study group being rather small (41 students only). It remains unclear whether use of the interactive material would have had the same impact and received a similar evaluation if the situation had allowed conducting the laboratory practical under normal circumstances and not under the COVID-19 lockdown during the spring of 2020 . 
Our findings support the use of educational IT-supported learning. The pedagogical principles, e-learning tools and learning elements can be applied in many other scientific areas and at many other learning institutions, from primary school to higher education.

\section{References}

Anderson, L. W., \& Krathwohl, D. R. (2001). A taxonomy for learning, teaching, and assessing: a revision of Bloom's taxonomy of educational objectives (Complete ed.). Longman, New York, USA

Articulate Global, I. (2020). Rise 360. Articulate. https://articulate.com/360/rise

Ausubel, D. P. (1967). Learning theory and classroom practice. Ontario Institute for Studies in Education. Ontario, Canada

Bandura, A. (1997). Self-efficacy: the exercise of control. W.H. Freeman. New York, USA.

Bandura, A., Barbaranelli, C., Caprara, G. V., \& Pastorelli, C. (1996, Jun). Multifaceted impact of self-efficacy beliefs on academic functioning. Child Dev, 67(3), 1206-1222.

Bjælde, O. E., Jørgensen, T. H., \& Lindberg, A. B. (2017). Continuous assessment in higher education in Denmark: Early experiences from two science courses. Dansk Universitetspædagogisk Tidsskrift, 12(23), 1-19.

Blackburn, R. A. R., Villa-Marcos, B., \& Williams, D. P. (2019). Preparing Students for Practical Sessions Using Laboratory Simulation Software. Journal of Chemical Education, 96, 153-158.

Churches, A. (01/04/09). Blooms Digital Taxonomy. Retrieved February 2021 from https://www.researchgate.net/publication/228381038 Bloom's Digital Taxonomy\#fullTextFileContent

Clark, R. C., \& Mayer, R. E. (2011). E-learning and the science of instruction: proven guidelines for consumers and designers of multimedia learning (3rd ed.). Pfeiffer essential resources for training and HR professionals, Pfeiffer, San Francisco, USA.

Costabile, M. (2020). Using online simulations to teach biochemistry laboratory content during COVID-19. Biochemistry and Molecular Biology Education, 48, 509-510.

Dahl, M. R., Hedegaard, E. R., \& Musaeus, P. (2013). Online farmakologi - i et virtuelt laboratorium. Læring og Medier (LOM), 11, 1-18.

Dyrberg, N. R., Treusch, A. H., \& Wiegand, C. (2017). Virtual laboratories in science education: students' motivation and experiences in two tertiary biology courses. Journal of Biological Education, 51(4), 358-374.

Furberg, A. (2016). Teacher support in computer-supported lab work: bridging the gap between lab experiments and students' conceptual understanding. International Journal of Computer-Supported Collaborative Learning volume 11, 89-113. 
Goudsouzian, L. K., Riola, P., Ruggles, K., Gupta, P., \& Mondoux, M. A. (2018). Integrating cell and molecular biology concepts: Comparing learning gains and self-efficacy in corresponding live and virtual undergraduate laboratory experiences. Biochemistry and Molecular Biology Education, 46(4), 361-372.

Hammond, J., \& Gibbons, P. (2005). What is scaffolding? In A. Burns \& H. de Silva Joyce (Eds.), Teachers' Voices: Explicitly Supporting Reading and Writing in the Classroom (pp. 8-16). National Centre for English Language Teaching and Research.

Harden, R. M., \& Laidlaw, J. M. (2013). Be FAIR to students: four principles that lead to more effective learning. Med Teach, 35(1), 27-31.

Hattie, J. (2009). Visible learning: a synthesis of over 800 meta-analyses relating to achievement. Routledge. London, United Kingdom.

Husnaini, S. J., \& Chen, S. J. (2019). Effects of guided inquiry virtual and physical laboratories on conceptual understanding, inquiry performance, scientific inquiry self-efficacy, and enjoyment. Physical Review Physics Education Research, 15,(1).

Jespersen, B., Tykocki, N. R., Watts, S. W., \& Cobbett, P. J. (2015). Measurement of smooth muscle function in the isolated tissue bath-applications to pharmacology research. J Vis Exp, (95), 52324.

Klassen, R. M., \& Klassen, J. R. L. (2018, Apr). Self-efficacy beliefs of medical students: a critical review. Perspect Med Educ, 7(2), 76-82.

Kolil, V. K., Muthupalani, S., \& Achuthan, K. (2020). Virtual experimental platforms in chemistry laboratory education and its impact on experimental self-efficacy. International Journal of Educational Technology in Higher Education, 17.

Likert, R. (1932). A technique for the measurement of attitudes. Archives of Psychology. 22, 140, 55.

Makransky, G., Thisgaard, M. W., \& Gadegaard, H. (2016). Virtual simulations as preparation for lab exercises: Assessing learning of key laboratory skills in microbiology and improvement of essential non-cognitive skills. PLoS One, 11 (6), e0155,0895.

Medina, M. S. (2017, Apr). Making Students' Thinking Visible During Active Learning. Am J Pharm Educ, 81(3), 41.

Reece, A. J., \& Butler, M. B. (2017). Virtually the same: A comparison of stem students content knowledge, course performance, and motivation to learn in virtual and face-to-face introductory biology laboratories. Journal of College Science Teaching, 46(3), 83-89.

Rutten, N., van Joolingen, W. R., \& van der Veen, J. T. (2012). The learning effects of computer simulations in science education. Computers and Education, 58, 136-153. 
Thisgaard, M., \& Makransky, G. (2017). Virtual Learning Simulations in High School: Effects on Cognitive and Non-cognitive Outcomes and Implications on the Development of STEM Academic and Career Choice. Front Psychol, 8, 805.

Tobin, M. A. (2020). Guide to Item Analysis. The Schreyer Institute for Teaching Excellence, Pennsylvania State University. Pennsylvania, USA. Retrieved October 2020 from http://www.schreyerinstitute.psu.edu/Tools/?q=Item\%20Analysis

Weaver, M. G., Samoshin, A. V., Lewis, R. B., \& Gainer, M. J. (2016). Developing Students' Critical Thinking, Problem Solving, and Analysis Skills in an Inquiry-Based Synthetic Organic Laboratory Course. Journal of Chemical Education, 93, 847-851.

Weinberg, R. S., Gould, D., \& Jackson, A. (1979). Expectations and performance: An empirical test of Bandura's self-efficacy theory. Journal of Sport Psychology, 1(4), 320-331.

Wilde, N., \& Hsu, A. (2019). The influence of general self-efficacy on the interpretation of vicarious experience information within online learning. International Journal of Educational Technology in Higher Education, 16(1), $1-20$.

Williams, D. (2011). What is assessment for learning? Studies in Educational Evaluation, 37, 3-14.

\section{Betingelser for brug af denne artikel}

Denne artikel er omfattet af ophavsretsloven, og der må citeres fra den.

Følgende betingelser skal dog være opfyldt:

- Citatet skal være i overensstemmelse med "god skik"

- Der må kun citeres „i det omfang, som betinges af formålet"

- Ophavsmanden til teksten skal krediteres, og kilden skal angives ift. ovenstående bibliografiske oplysninger

(C) Copyright

DUT og artiklens forfatter
Udgivet af Dansk Universitetspædagogisk Netværk 